\title{
Induction of apoptotic death and retardation of neuronal differentiation of human neural stem cells by sodium arsenite treatment
}

\author{
Vladimir N. Ivanov*, Tom K. Hei \\ Center for Radiological Research, Department of Radiation Oncology, College of Physicians and Surgeons, Columbia University, \\ 630 West 168th Street, NY 10032, United States
}

\section{A R T I C LE IN F O R M A T I O N}

\section{Article Chronology:}

Received 20 October 2012

Received in revised form

26 November 2012

Accepted 27 November 2012

Available online 5 December 2012

\section{Keywords:}

Neural stem cells

AKT

ERK

JNK

Sodium arsenite

\begin{abstract}
A B S T R A C T
Chronic arsenic toxicity is a global health problem that affects more than 100 million people worldwide. Long-term health effects of inorganic sodium arsenite in drinking water may result in skin, lung and liver cancers and in severe neurological abnormalities. We investigated in the present study whether sodium arsenite affects signaling pathways that control cell survival, proliferation and neuronal differentiation of human neural stem cells (NSC). We demonstrated that the critical signaling pathway, which was suppressed by sodium arsenite in NSC, was the protective PI3K-AKT pathway. Sodium arsenite $(2-4 \mu \mathrm{M})$ also caused down-regulation of Nanog, one of the key transcription factors that control pluripotency and self-renewal of stem cells. Mitochondrial damage and cytochrome-c release induced by sodium arsenite exposure was followed by initiation of the mitochondrial apoptotic pathway in NSC. Beside caspase-9 and caspase-3 inhibitors, suppression of JNK activity decreased levels of arsenite-induced apoptosis in NSC. Neuronal differentiation of NSC was substantially inhibited by sodium arsenite exposure. Overactivation of JNK1 and ERK1/2 and down-regulation of PI3K-AKT activity induced by sodium arsenite were critical factors that strongly affected neuronal differentiation. In conclusion, sodium arsenite exposure of human NSC induces the mitochondrial apoptotic pathway, which is substantially accelerated due to the simultaneous suppression of PI3K-AKT. Sodium arsenite also negatively affects neuronal differentiation of NSC through overactivation of MEK-ERK and suppression of PI3K-AKT.
\end{abstract}

(c) 2012 Elsevier Inc. All rights reserved.

\footnotetext{
Abbreviations: EGF, epidermal growth factor; EGFR, epidermal growth factor receptor; ERK, extracellular-signal-regulated kinases; ESC, embryonic stem cells; FACS, fluorescence-activated cell sorter; FGF2, fibroblast growth factor-2 (basic); IGF1, insulin-like growth

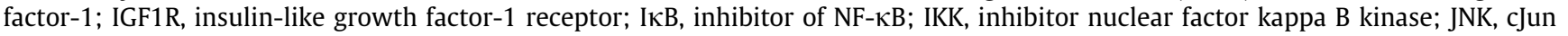
$\mathrm{N}$-terminal kinase; LEHD, N-acetyl-Leu-Glu-His-Asp-CHO (aldehyde); MAPK, mitogen-activated protein kinase; MEK, MAPK/ERK kinase; NF- $\kappa B$, nuclear factor kappa B; NSC, neural stem cells; PARP-1, poly (ADP-ribose) polymerase-1; PI, propidium iodide; PI3K, phosphoinositide 3-kinase; ROS, reactive oxygen species; PPP, picropodophyllin; STAT, signal transducers and activators of transcription; TNF $\alpha$, tumor necrosis factor; zVAD, carbobenzoxy-valyl-alanyl-aspartyl-[O-methyl]-fluoromethylketone

${ }^{*}$ Corresponding author. Fax: +1212305 3229.

E-mail address: vni3@columbia.edu (V.N. Ivanov).
} 


\section{Introduction}

Chronic arsenic toxicity is a global environmental health problem that affects millions of people from Bangladesh to the United States. Arsenic is a transplacental carcinogen in rodents and probably in humans [1,2]. Long-term health effects of exposure to inorganic arsenite may result in skin, lung and liver cancers, cardiovascular diseases and neurological abnormalities [3,4]. Furthermore, arsenic is a well-characterized teratogen in animal models, inducing a general embryotoxicity and negatively affecting embryonic neurogenesis [5]. In the United States, the EPA has set the arsenic standard for drinking water as $10 \mathrm{ppb}(10 \mu \mathrm{g} / \mathrm{L})$ to protect consumers served by public water systems from the effects of arsenic exposure. Contaminated groundwater in some parts of the world may contain arsenic at concentration as high as $5 \mathrm{mg} / \mathrm{L}[6,7]$, being associated with substantial increased risk for wide array of diseases including cancer. At biochemical levels, sodium arsenite at high doses $(>5 \mu \mathrm{M})$ represents a general cell poison acting as a sulfhydryl reagent, which binds to the free thiol groups of numerous enzymes, inhibiting their functions and also significantly depleting levels of glutathione (GSH) that destroys the cell metabolism [8]. Furthermore, sodium arsenite is a strong inducer of production of reactive oxygen species causing oxidative stress, mitochondrial damage and a broad range of pathological conditions. These complementary negative actions of sodium arsenite finally result in the induction of cell death [9-11]. Chronic arsenite exposure, which occurred in most cases at lower doses (1-4 $\mu \mathrm{M})$, could affect the crucial signaling pathways, transcription factors and gene expression in different types of cells, including stem cells.

The self-renewal of embryonic stem cells and the maintenance of their pluripotency are dependent on multifactorial stimulation of the cell signaling pathways by a combination of cytokines and growth factors that regulate "stemness"-specific gene expression. These genes encode key transcription factors Oct4, Sox2, Nanog, Klf4 and c-Myc [12,13]. Transcription factors Sox2 and Nanog [14] in concert with Ars2 (arsenic-resistance protein 2), which was recently demonstrated as a transcriptional regulator of Sox2 expression [15], play the central role in gene regulation in multipotent neural stem cells (NSC), coordinating expression of numerous genes and providing a dynamic suppression of the differentiation program. To prove our hypothesis regarding specific targets of sodium arsenite, which regulate self-renewal, survival and differentiation of NSC, we elucidated the effects of arsenite treatment on signaling pathways in human NSC with special attention to regulation of protein levels of Sox2, Nanog and Ars2.

During embryogenesis, transplacental arsenite exposure might negatively affect proliferation and survival of embryonic NSC. Furthermore, NSC also persist in two specialized niches in the adult brain initiating adult neurogenesis that is critically important for functional recovery in the brain after injury or disease $[14,16]$. The blood brain barrier in healthy adults quite effectively, but not absolutely, protects against arsenite trafficking in the brain [17]. However, the blood brain barrier is not fully developed until the age of six months in humans, making a childs brain especially vulnerable to toxic exposure [18]. We have suggested in the present study that arsenite exposure might target both embryonic and postnatal neurogenesis via interference and interaction with cell signaling pathways, including induction of death signaling in human NSC.

There is evidence to indirectly support this suggestion. Animal experiments demonstrated sensorimotor and cognitive behavioral deficits in mice and rats after prolonged arsenic treatment [19]. Chronic arsenic exposure from drinking water negatively affected neurobehavioral development in human adolescence [6]. The epidemiological studies of human populations in Bangladesh exposed to sodium arsenite in drinking water further revealed an inverse association between arsenic dose and IQ performance [20].

We demonstrate in our study a differential response of several signaling pathways to sodium arsenite exposure in NSC. We also elucidate a mechanism of the apoptotic death induced by sodium arsenite in NSC, involving the mitochondrial death pathway as the main player. The maintenance of human NSC in cell culture is ultimately dependent on the presence of several growth factors, such as FGF2, EGF and IGF1/2 that are linked with the regulation of expression of key transcription factors, Sox2 and Nanog [21]. Removing FGF2 and EGF from the cell culture media induced neuronal differentiation [22]. A special interest was to investigate the effects of sodium arsenite exposure on the neuronal pathway of differentiation of human NSC. We demonstrate in this study that chronic arsenic exposure dramatically and negatively affects the neuronal pathway of differentiation of NSC based on the opposite roles for ERK1/2 and JNK activation. Revealing a connection between stem cell biology and environmental health studies will allow us to better understand mechanisms of neurodegenerative diseases.

\section{Materials and methods}

\section{Reagents}

Sodium arsenite, fibronectin, laminin and polyornithine were obtained from Sigma-Aldrich (St. Louis, MO, USA). PI3K inhibitor LY294002, IKK inhibitor BMS345541, STAT3 inhibitor-6 S3I-201 (also known as NSC 74859), IGF-1R kinase inhibitor picropodophyllin (PPP), PI3K inhibitor LY294002, MEK inhibitor U0126, MAPK p38 inhibitor SB203580, JNK inhibitor SP600125 and caspase inhibitors zVAD-fmk, LEHD and IETD were purchased from Calbiochem (La Jolla, CA, USA).

\section{Human embryonic neural stem cells in culture}

Cryopreserved human embryonic neural stem cells (NSC) were obtained from Gibco/Life Technologies (Carlsbad, CA, USA) as a commercially available product (N7800-200). The cells were derived from NIH approved H9 (WA09) human embryonic stem cells. The cells were plated in 6 -well culture plates coated with fibronectin and incubated at $37{ }^{\circ} \mathrm{C}$ in complete growth medium NSC/SFM, which contained serum-free DMEM/F12 supplemented with $2 \mathrm{mM}$ GlutaMAX, bFGF $(20 \mathrm{ng} / \mathrm{ml})$, EGF $(20 \mathrm{ng} / \mathrm{ml})$ and StemPRO neural supplement (2\%). All reagents were obtained from Gibco/Life Technologies (Carlsbad, CA, USA).

\section{Neuronal differentiation of human neural stem cells in culture}

Neural stem cells were plated on polyornithine- and laminincoated 6-well plates, which contained similarly coated cover 
slips, in complete NSC/SFM. After 2 days, neuronal differentiation was initiated by neuronal differentiation media, which contain Neurobasal medium, B-27 serum-free supplement (2\%) and 2 mM GlutaMAX (Gibco/Life Technologies). Medium was changed every two days. A neuronal phenotype was confirmed using immunofluorescence detection 10 days after initiation of differentiation.

\section{Immunocytochemistry analysis}

Cells were fixed with $4 \%$ paraformaldehyde in PBS for $60 \mathrm{~min}$. Immunochemical staining was performed using standard protocols. Cells were stained for the undifferentiated NSC marker, nestin (using mAb from Millipore, Temecula, CA, USA) and for the neuronal marker, doublecortin using Ab from Cell Signaling, (Danvers, MA, USA). Additional markers include Sox2, phospho(T202,Y204)-ERK, phospho-JNK, phospho-(S73)-cJun (using Abs from Cell Signaling) and pyruvate dehydrogenase (using $\mathrm{Ab}$ from Binding Site, UK). The secondary Abs were Alexa Fluor 594 goat anti-mouse IgG and Alexa Fluor 488 goat anti-rabbit IgG from Molecular Probes/Life Technologies (Carlsbad, CA, USA). A laser scanning confocal microscope (Nikon TE 2000 with EZ-C1 software, Tokyo, Japan) was used for immunofluorescence image analysis.

\section{Apoptosis studies}

For induction of apoptosis, cells were exposed to sodium arsenite $(1-10 \mu \mathrm{M})$ alone or in the presence of small molecule inhibitors of cell signaling pathways. Apoptosis was then assessed by PI staining by quantifying the percentage of hypodiploid nuclei (pre-G1) using FACS analysis or by quantifying the percentage of Annexin-V-FITC-positive cells (BD Pharmingen, San Diego, CA). Flow cytometric analysis was performed on a FACS Calibur flow cytometer (Becton Dickinson) using the CellQuest program. The trypan blue exclusion test was used for determination of cell viability and total death levels.

\section{Western blot analysis}

Total cell lysates ( $50 \mu \mathrm{g}$ protein) were resolved on SDS-PAGE, and processed according to standard protocols. The monoclonal antibodies used for Western blotting included: anti- $\beta$-actin (Sigma, St. Louis, MO, USA); anti-caspase-8, anti-caspase-9, and anti-caspase-3 (Cell Signaling, Danvers, MA, USA). The polyclonal antibodies used included anti-phospho-p44/p42 MAP kinase (T202/Y204) and anti-p44/p42 MAP kinase; anti-phospho-JNK and anti-JNK1-3; anti-phospho-cJun (S73) and anti-cJun; antiphospho-AKT (S473) and anti-AKT; anti-phospho-p65 (S536) NF- $\kappa$ B and anti-p65 NF- $\kappa$ B, anti-phospho-STAT3 (Y705) and anti-STAT3; anti-phospho-FOXO3A (S253) and anti-FOXO3A; anti- $\beta$-Catenin, anti-Oct4, anti-Sox2, anti-Nanog and antiPARP-1 (Cell Signaling, Danvers, MA, USA); anti-Ars2 (Santa Cruz Biotechnology, CA, USA); anti-HO-1 (Enzo Life Sciences, Plymouth Meeting, PA, USA). The secondary antibodies were conjugated to horseradish peroxidase; signals were detected using the ECL system (Thermo Scientific, Rockford, IL, USA).

\section{Statistical analysis}

Data from four to five independent experiments were calculated as means and standard deviations. Comparisons of results between treated and control groups were made by the Students' $t$-tests. A $p$-value of 0.05 or less between groups was considered significant.

\section{Results}

\section{Sodium arsenite modulates signaling pathways that control self-renewal and survival of human neural stem cells}

In our study we address three main questions regarding effects of sodium arsenite exposure on human NSC: (i) Does arsenite treatment induce apoptotic pathways in NSC? (ii) Does arsenite additionally accelerate pro-apoptotic commitment in NSC via suppression of pro-survival pathways? (iii) What are the effects of arsenite treatment on neuronal differentiation of NSC?

Characteristic features of human NSC include nuclear expression of key transcription factor Sox 2 and cytoplasmic expression of nestin, undifferentiated NSC/early neuroprogenitor cell marker (Fig. 1A and B). Sodium arsenite treatment (1-4 $\mu \mathrm{M}$ ) suppressed logarithmic phase growth of adherent cultures of NSC (Fig. 1C) and substantially increased levels of cell death in confluent cultures (Fig. 1D). A significant difference in growth of control and sodium arsenite treated (1-4 $\mu \mathrm{M}$ ) cells was evident 1-3 days after treatment. Furthermore, dose-dependent effects of arsenite treatment on NSC survival were well pronounced for concentrations $1 \mu \mathrm{M}$ versus $4 \mu \mathrm{M}$. The resulting dramatic differences in cell survival of the control and arsenite-treated NSC ( $48 \mathrm{~h}$ of exposure) are demonstrated in Fig. 1D-F. Sodium arsenite induced massive flotation of dead neural stem cells (Fig. 2A). Finally, many human NSC died $24-48 \mathrm{~h}$ following arsenite exposure $(2-6 \mu \mathrm{M})$ in a dose-dependent manner via apoptotic mechanism (Fig. 2B). Levels of total cell death were higher compared to apoptotic levels (Fig. 2B, right column), indicating a possible role for necrosis in a subpopulation of NSC after sodium arsenite treatment.

To determine signaling pathways and regulatory proteins that were targeted by sodium arsenite treatment of NSC with final induction of apoptosis, we performed Western blot analyses of total protein extracts of NSC before and after arsenite exposure (Fig. 3). A distinguishing feature of arsenite treatment ( $6 \mathrm{~h}$ ) was a significant upregulation of levels of active forms of phosphoERK2 and phospho-JNK1 (while the level of active neuro-specific JNK3 was actually down-regulated) that was followed by enormous activation of cJun (Fig. 3A). Analysis of an immunofluorescent image confirmed upregulation of active phospho-ERK levels upon arsenite treatment of human NSC (Fig. 3B). This process was accompanied by a strong decrease in active phospho-AKT levels and, consequentially, by a decrease of AKTdependent phosphorylation of FOXO3A (Fig. 3A) that could additionally release proapoptotic activity of FOXA3A [23]. Total beta-catenin protein levels were high and relatively stable during the initial treatment of NSC by arsenite (Fig. 3A). Only a modest decrease in $\beta$-catenin levels was observed $16 \mathrm{~h}$ after arsenite exposure (see Fig. 4A). Furthermore, in contrast to embryonic 


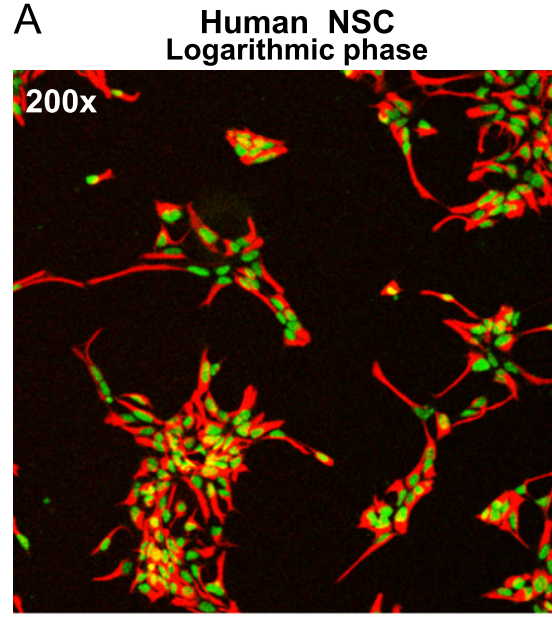

SOX-2 (green), Nestin (red)

\section{B Human NSC}

at $70 \%$ confluency



C

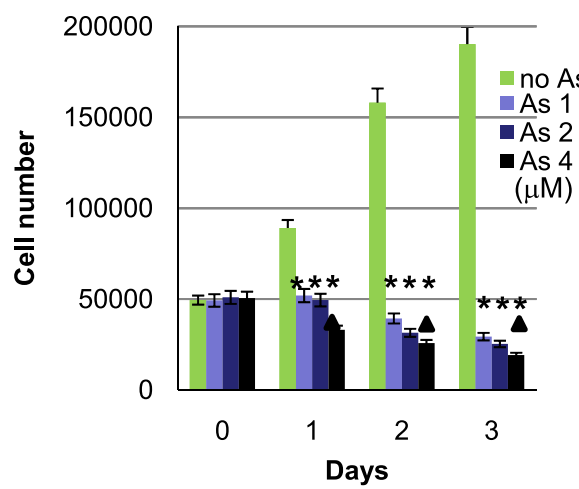

D

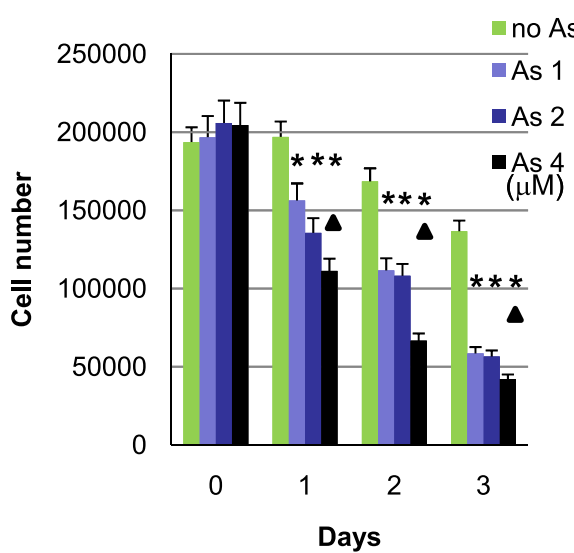

E
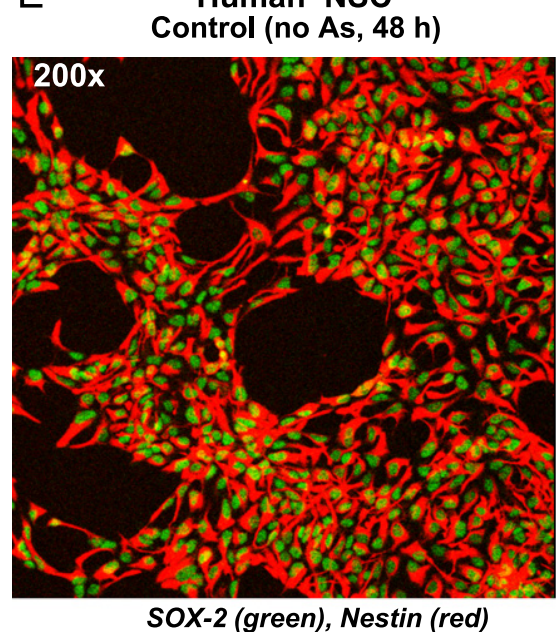

F

Human NSC

Surviving cells (As $4 \mu \mathrm{M}, 48 \mathrm{~h}$ )

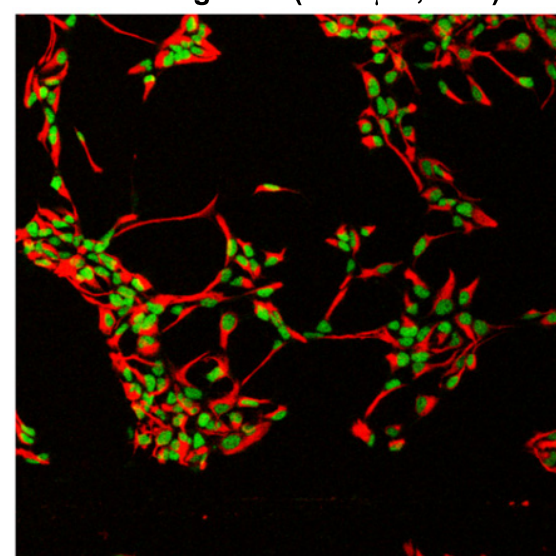

Fig. 1 - Effects of sodium arsenite treatment on growth and survival of human neural stem cells (NSC). (A, B, E and F) Confocal analysis of immunofluorescent images of NSC was performed using monoclonal antibody against nestin, an early neuroprogenitor cell marker (red), and polyclonal antibody against Sox2, a pluripotency marker (green). (C and D) Determination of human NSC growth and survival was performed in the absence or in the presence of increased doses of sodium arsenite (1-4 $\mu \mathrm{M}$ ). Sodium arsenite was added to NSC cultures at the logarithmic phase (panels A and C) or at 70\% confluency (panels B and $D$ ) at day 0 for the next 3 days. Numbers of live cells attached to fibronectin matrix were determined. Pooled results of five independent experiments are shown in panels $C$ and $D$. Error bars represent means + SD. Statistically significant differences in cell number between control and arsenite treated (1-4 $\mu \mathrm{M})$ cell cultures are indicated by the stars. Statistically significant differences in cell survival between cell cultures treated with $4 \mu \mathrm{M}$ arsenite, compared to cultures treated with $1 \mu \mathrm{M}$ arsenite, are indicated by the triangles ( $p<0.05$, Student's $t$-test). Images of control NSC and surviving NSC $48 \mathrm{~h}$ after sodium arsenite exposure are shown on panels $E$ and $F$.

stem cells after sodium arsenite exposure (data not shown), activation of Stat3 via Tyr705 phosphorylation was not notably affected by arsenic treatment of NSC (Fig. 3A). Interestingly, a modest upregulation of Sox2 and Ars2 levels was actually observed $6 \mathrm{~h}$ after arsenite treatment (Fig. $3 \mathrm{~A}$ and $\mathrm{C}$ ) that coincided with cJun activation at these doses of arsenite. Indeed, SP600125 $(20 \mu \mathrm{M})$, a specific inhibitor of JNK, decreased levels of active JNK-cJun that were induced by sodium arsenite, and consequently down-regulated Ars2 and Sox2 levels (Fig. 3C). Nanog protein levels were relatively stable after treatment with $1-4 \mu \mathrm{M}$ arsenite for $6 \mathrm{~h}$ (Fig. 3A), but were substantially decreased after treatment with $2-4 \mu \mathrm{M}$ arsenite for $16 \mathrm{~h}$ (see
Fig. 4C). Nestin protein levels were gradually decreased after arsenite treatment (Fig. 3A).

Furthermore, treatment with low doses of arsenite notably increased phosphorylation of IKK $\alpha / \beta$ (inhibitor nuclear factor kappa $B$ kinase $\alpha / \beta$ ) and its main target $I \kappa B \alpha$ that was accompanied by a modest increase of active NF- $\kappa B$ p65phospho-Ser536 levels. In contrast, specific inhibition of IKK and down-regulation of NF- $\kappa \mathrm{B}$ p65-phospho-Ser536 levels by BMS345541 $(10 \mu \mathrm{M})$ were observed (Fig. 3D). Ars2 levels were increased in parallel to IKK-NF- $\kappa \mathrm{B}$ activation and also suppressed with BMS345541, further highlighting a possible NF- $\kappa B-d e p e n-$ dent manner of regulation of Ars2 expression. In contrast, Sox2 

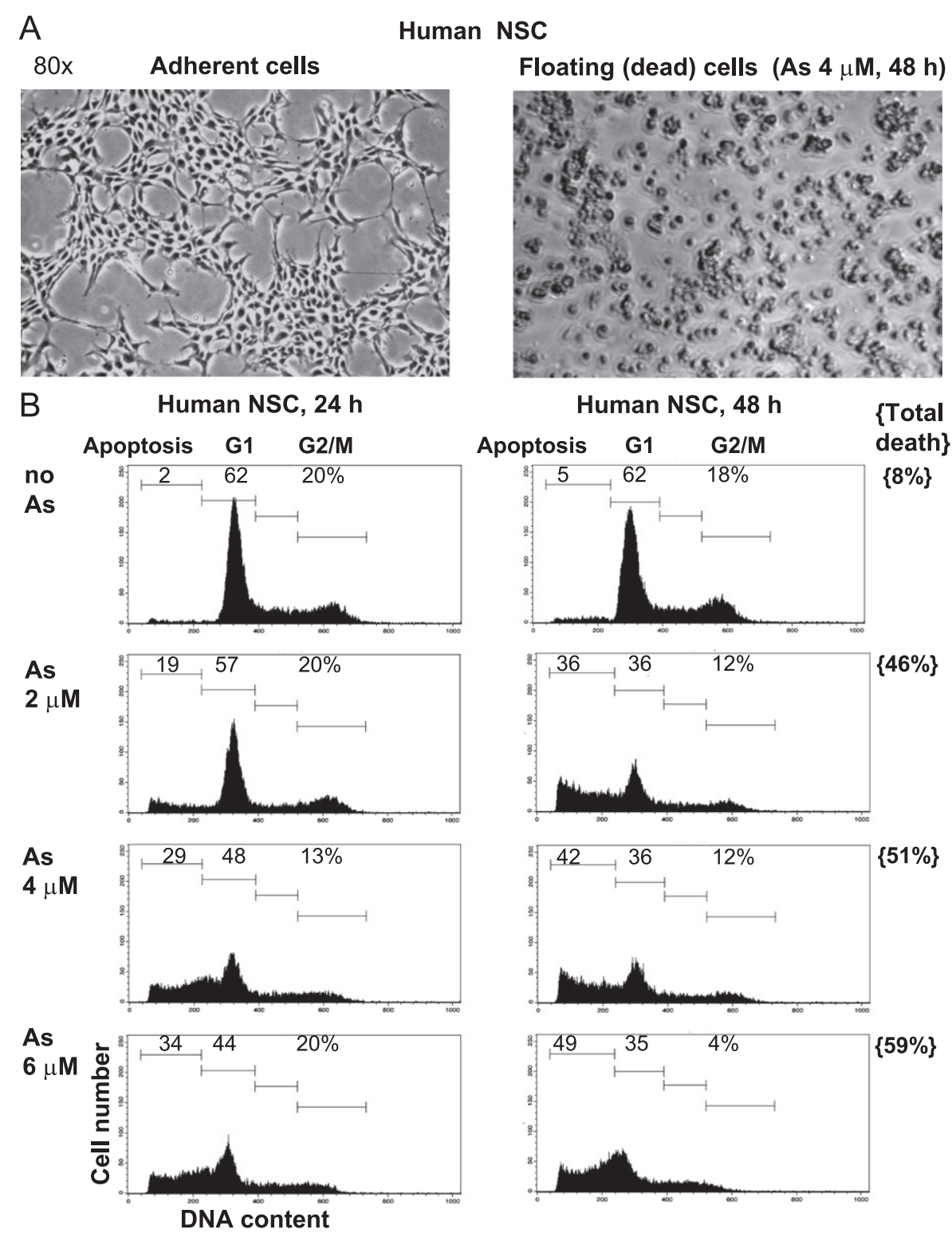

Fig. 2 - Dose-dependent effects of sodium arsenite treatment on induction of apoptosis in human NSC. (A) Phase contrast microscopy of human NSC (cultured as adherent cells) in the absence and in the presence of $4 \mu \mathrm{M}$ sodium arsenite, $48 \mathrm{~h}$ of exposure. (B) Cell cycle-apoptosis analysis of human NSC 24-48 h after treatment by sodium arsenite (2-6 $\mu \mathrm{M})$. Cells were stained by propidium iodide and analyzed by flow cytometry. A typical experiment (one of four) is presented. Determination of total cell death levels $48 \mathrm{~h}$ after sodium arsenite treatment was performed using Trypan blue staining.

did not respond to IKK inhibition (Fig. 3D). Sox2, which was upregulated $6 \mathrm{~h}$ after arsenite treatment, returned to relatively stable levels after prolonged 16-h arsenite exposure (Fig. 4C). Immunostaining with anti-Sox2 Ab further confirmed this observation: nuclear levels of Sox2 were relatively stable in surviving cells, while the total number of attached cells notably decreased $24 \mathrm{~h}$ after arsenic treatment (see Fig. 1E and F).

A decrease in phospho-(Ser473)-AKT levels after extended treatment (16 h) of NSC with arsenite was followed by a modest decrease in $\beta$-catenin levels that was more pronounced after combined treatment of arsenite and LY294002, a PI3K-AKT inhibitor (Fig. 4A). Furthermore, extended arsenite exposure of NSC resulted in a cytochrome-c release from mitochondria to cytosol, and hemeinduced upregulation of heme oxygenase-1 (HO-1), a protective enzyme with a general anti-apoptotic activity. Addition of IGF1 (as a strong inducer of PI3K-AKT) $30 \mathrm{~min}$ before arsenite to cell cultures blocked cytochrome-c release and HO-1 activation (Fig. 4B), resulting in suppression of apoptotic commitment. Activation of p53 (via Ser20 phosphorylation) was a characteristic feature of sodium arsenite treatment of NSC at relatively low doses $(1-2 \mu \mathrm{M})$ (Fig. 3C). Finally, caspase-9 cleavage and activation was followed by caspase-9/caspase-3 directed apoptosis, including a cleavage of PARP-1 (Fig. 4C). Immunostaining of mitochondrial pyruvate dehydrogenase further demonstrated a pronounced down-regulation of levels of this critical enzyme after sodium arsenite exposure, reflecting damage of mitochondria (Fig. 4D). Annexin-V-FITC and PI staining independently confirmed arsenite-induced apoptotic commitment of NSC and enhancing effects of PI3K-AKT inhibition on 


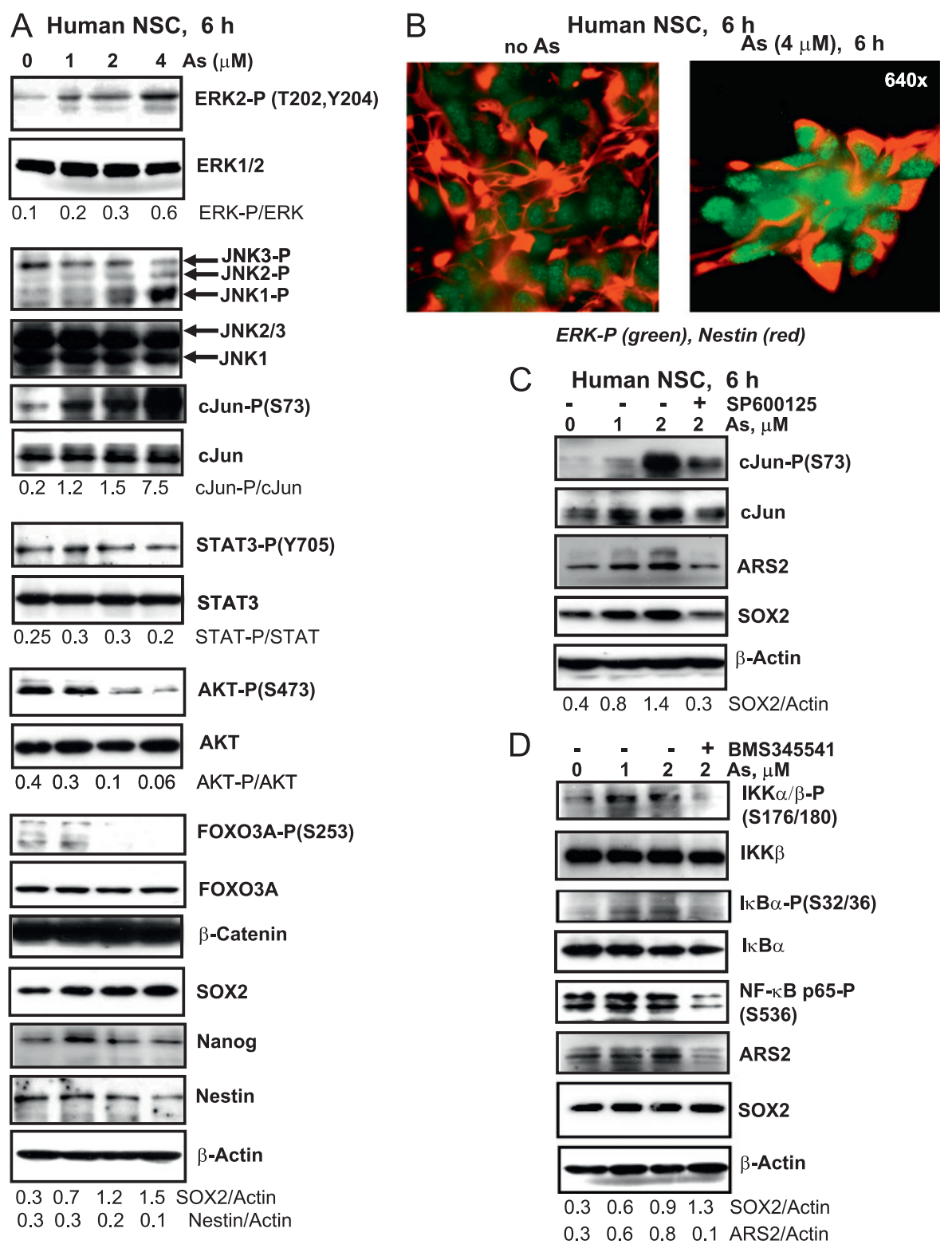

Fig. 3 - Effects of sodium arsenite treatment on the main signaling pathways in human NSC. (A, C and D) Signaling proteins and transcription factors were detected using Western blot analysis $6 \mathrm{~h}$ after treatment with increased doses of sodium arsenite, alone or in combination with SP600125 $(20 \mu \mathrm{M})$ and BMS345541 $(10 \mu \mathrm{M})$. A ratio of phospho-protein/total protein is indicated for ERK, cJun, STAT3 and AKT. A ratio protein/actin is indicated for nestin, SOX2 and ARS2. (B) Analysis of immunofluorescent images of non-treated (control) and sodium arsenite $(4 \mu \mathrm{M})$ treated NSC. Cells were stained with anti-phospho-ERK (green) and anti-nestin (red) Abs. (For interpretation of the references to color in this figure legend, the reader is referred to the web version of this article.)

arsenite-induced cell death levels, when apoptosis was followed by increasing levels of secondary necrosis (Fig. 4E). In summary, pronounced proapoptotic effects of sodium arsenite exposure for human NSC were observed, due to activation of the caspase-9/ caspase-3-dependent mitochondrial apoptotic pathway and a partial suppression of the protective PI3K-AKT pathway.

Effects of combined treatment of sodium arsenite with small molecule inhibitors on cell survival and apoptosis of NSC

To further determine a differential role of signaling pathways in modulating effects of sodium arsenite on cell cycle and apoptosis of
NSC, we used small molecule inhibitors, alone or in combination with sodium arsenite (Fig. 5). Inhibition of PI3K-AKT and IKK-NF- $\mathrm{KB}$ by LY294002 and BMS345541, respectively, induced pronounced apoptosis in NSC $24 \mathrm{~h}$ after treatment (Fig. 5A), while inhibition of MEK-ERK by U0126 and JNK by SP600125 did not demonstrate a notable proapoptotic response. PARP-1 cleavage further confirmed caspase-3-dependent apoptosis induced either by sodium arsenite, or by LY294002 and BMS345541. In contrast, SP600125 and U0126 did not induce PARP-1 cleavage (Fig. 5C). Both a pan-caspase inhibitor zVAD-fmk $(50 \mu \mathrm{M})$ and a caspase-9 inhibitor Ac-LEHDCHO $(50 \mu \mathrm{M})$ suppressed arsenite-induced apoptosis (Fig. 5B). Combined treatment with arsenite $(2 \mu \mathrm{M})$ and LY294002 $(40 \mu \mathrm{M})$, or with arsenite and BMS345541 $(10 \mu \mathrm{M})$ further increased the 

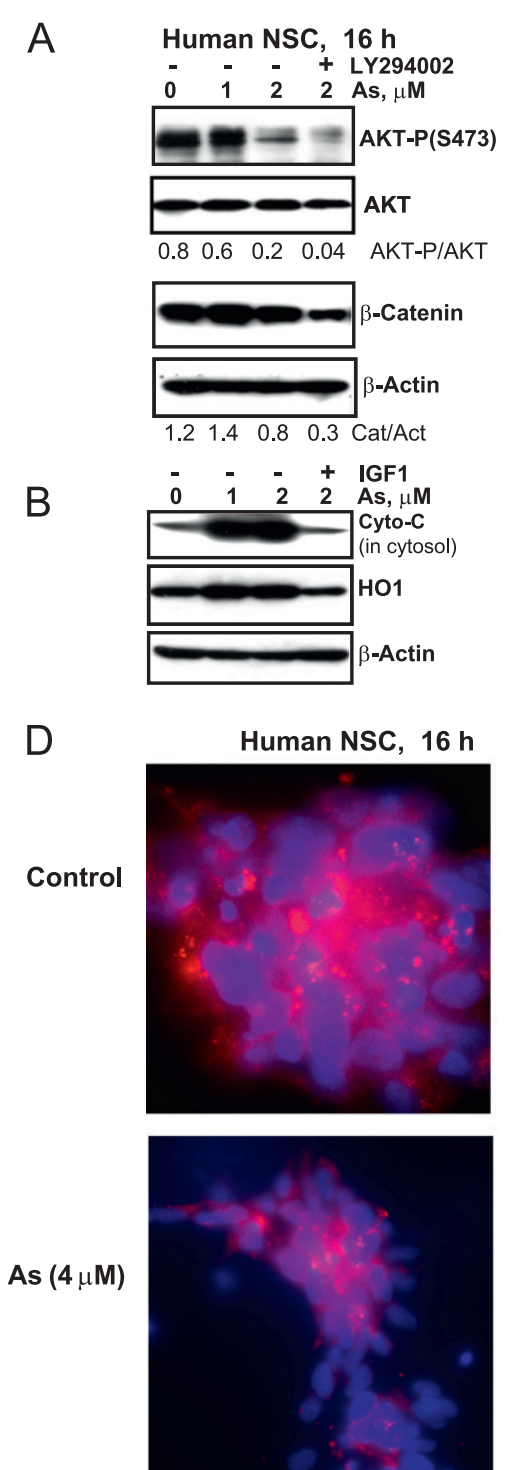

Mitochondrial Pyruvate dehydrogenase (red), DAPI (blue)
C Human NSC, $16 \mathrm{~h}$

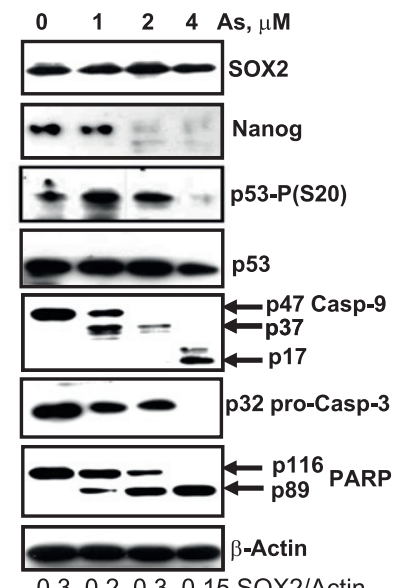

$\mathrm{E}$
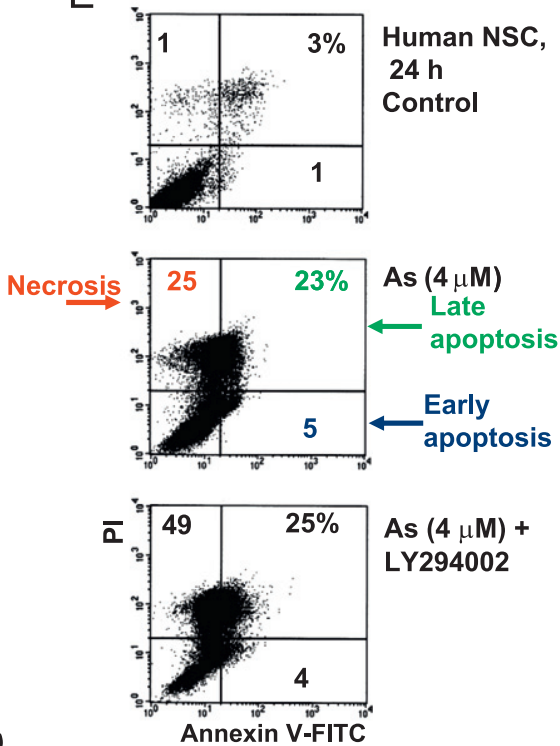

Fig. 4 - (A-C) Signaling proteins and transcription factors were detected using Western blot analysis $16 \mathrm{~h}$ after treatment with increased doses of sodium arsenite, alone or in combination LY294002 (40 $\mu \mathrm{M})$ and IGF1 (40 ng/ml). Determination of cytochrome-c levels (panel B) was performed in cytosol, while total protein extract was used for all other cases. (D) Immunostaining of mitochondrial pyruvate dehydrogenase (red) in the control and arsenite-treated NSC. The nuclei were stained by DAPI (blue). (E) Annexin-V-FITC and PI staining of control and arsenite (As) treated NCS was followed by FACS analysis. The percentages of necrotic, late-apoptotic and early-apoptotic cells are indicated. (For interpretation of the references to color in this figure legend, the reader is referred to the web version of this article.)

proapoptotic response of human NSC $24-48 \mathrm{~h}$ after treatment (Fig. 5B). In contrast, suppression of JNK activity by SP600125 $(20 \mu \mathrm{M})$ decreased levels of arsenite-induced apoptosis (Fig. 5B), highlighting a pro-apoptotic balance of JNK activation after arsenite treatment of NSC (Fig. 3A). Immunostaining of human NSC after combined treatment with arsenite and LY294002 or BMS345541 strongly demonstrated a decreased number of surviving cells attached to the laminin matrix (Fig. 5D).

Taken together, these data further demonstrated proapoptotic features of arsenite treatment in human NSC based induction of the mitochondrial death pathway in concert with suppression of PI3K-AKT and activation of JNK (mostly, JNK1) accompanied by phosphorylation of cJun, which could also be involved in acceleration of the mitochondrial apoptotic pathway [24]. However, there was a profound difference in regulation of expression of Sox2 in human NSC compare to ESC linked with the absence of negative effects of low doses of arsenite on Sox2 protein levels in NSC. In contrast, Nanog protein levels were significantly down-regulated in both mouse ESC (data not shown) and human NSC after extended sodium arsenite treatment (see Fig. 4C).

\section{Alteration of neuronal differentiation of human NSC in the presence of sodium arsenite}

Removing FGF2 and EGF from the NSC media induced neuronal differentiation of human NSC (Fig. 6) that was accompanied by 

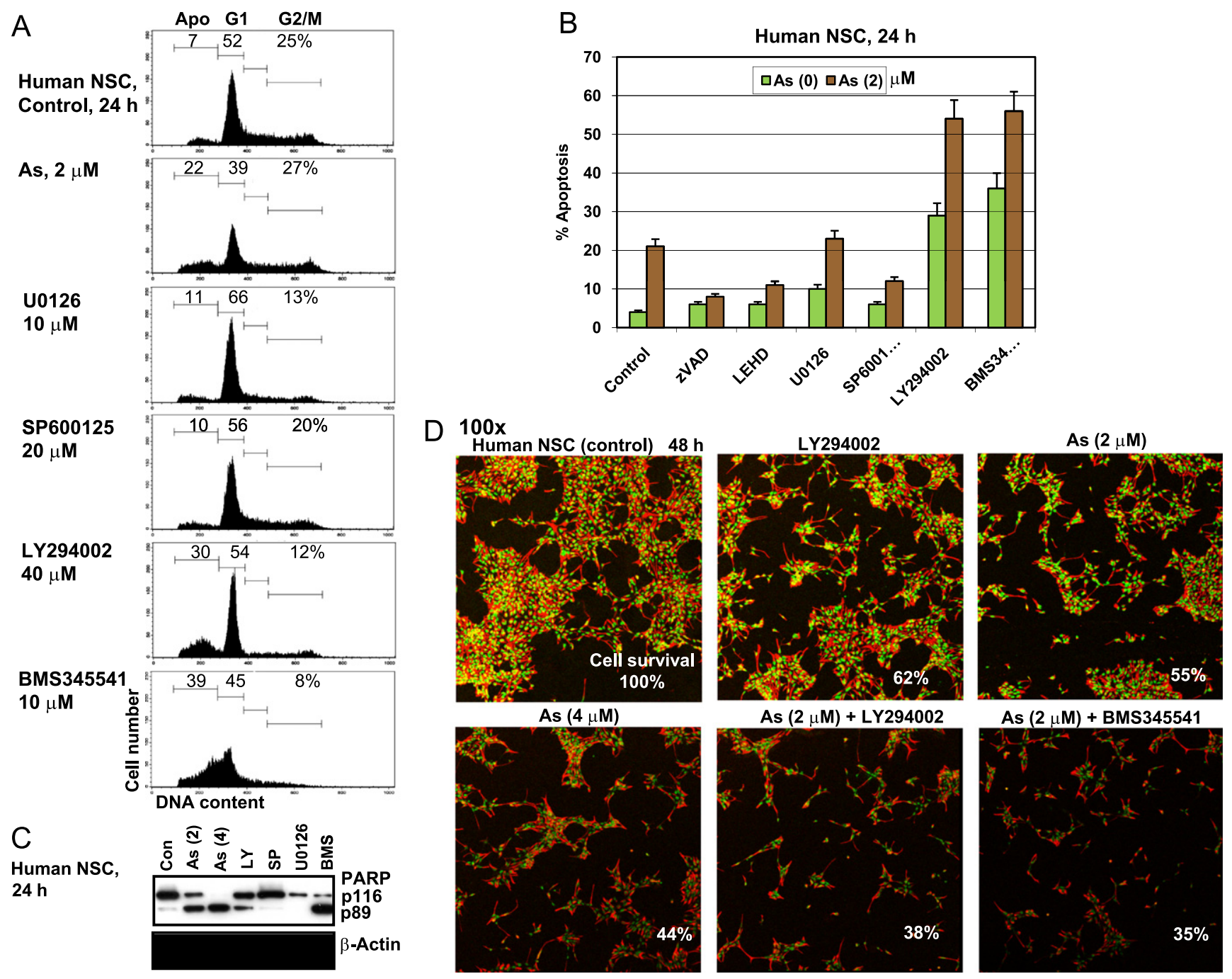

Fig. 5 - Effects of combined treatment of small molecule inhibitors and sodium arsenite on cell cycle and apoptosis of human NSC. (A and B) Cell cycle-apoptosis analysis was performed after treatment of human NSC with indicated inhibitors alone or in combination with $2 \mu \mathrm{M}$ sodium arsenite. Pan-caspase inhibitor zVAD-fmk (40 $\mu \mathrm{M})$ and caspase-9 inhibitor LEHD (40 $\mu \mathrm{M})$ were also used. PI staining of DNA and FACS analysis were performed $24 \mathrm{~h}$ after the indicated treatment. A typical experiment is presented in panel $A$; pooled results of four independent experiments are shown in panel B. Error bars represent means \pm S.D. $(p<0.05$, Student's $t$-test). (C) Western blot analysis of PARP-1 cleavage after indicated treatments of human NSC. Beta-actin was used as a loading control. (D) Self-renewal of human NSC in the absence (control) and in the presence of sodium arsenite ( $2 \mu \mathrm{M}$ ) or in combinations of LY294002 $(40 \mu \mathrm{M})$ and sodium arsenite $(2 \mu \mathrm{M})$; BMS345541 $(10 \mu \mathrm{M})$ and sodium arsenite $(2 \mu \mathrm{M})$. Confocal analysis of immunofluorescent image of human NCS was performed using monoclonal antibody against nestin (red) and polyclonal antibody against Sox2 (green). Relative cell survival is indicated. (For interpretation of the references to color in this figure legend, the reader is referred to the web version of this article.)

high levels of cell death. The gradual disappearance of an early neuroprogenitor cell marker, nestin (red), which was substituted with neuro-specific marker, doublecortin (green) was evident in surviving cells (Fig. 6). The presence of sodium arsenite at dose $2 \mu \mathrm{M}$ and especially at $4 \mu \mathrm{M}$ significantly retarded this process with a dramatic decrease in a green/red ratio (a ratio of the number of doublecortin-positive green cells to the number of nestin-positive red cells) and in a relative cell survival. Average cell survival of control or arsenite-treated differentiating cells was determined by direct counting cells that were attached to the laminin matrix in six microscopic areas 10 days after initiation of differentiation using immunostaining. Survival of control differentiating cells (in the absence of sodium arsenite) was referred to as $100 \%$ (Fig. 6). Substantially increased levels of phospho-JNK were also observed in sodium arsenite-treated cells (Fig. 6, right panel). As expected, numerous apoptotic nuclei were detected in differentiating cell cultures. The initial cell density of NSC could affect the rate of neuronal differentiation, which was down-regulated in conditions of high confluency (Supplementary Fig. 1A and B). On the other hand, negative 


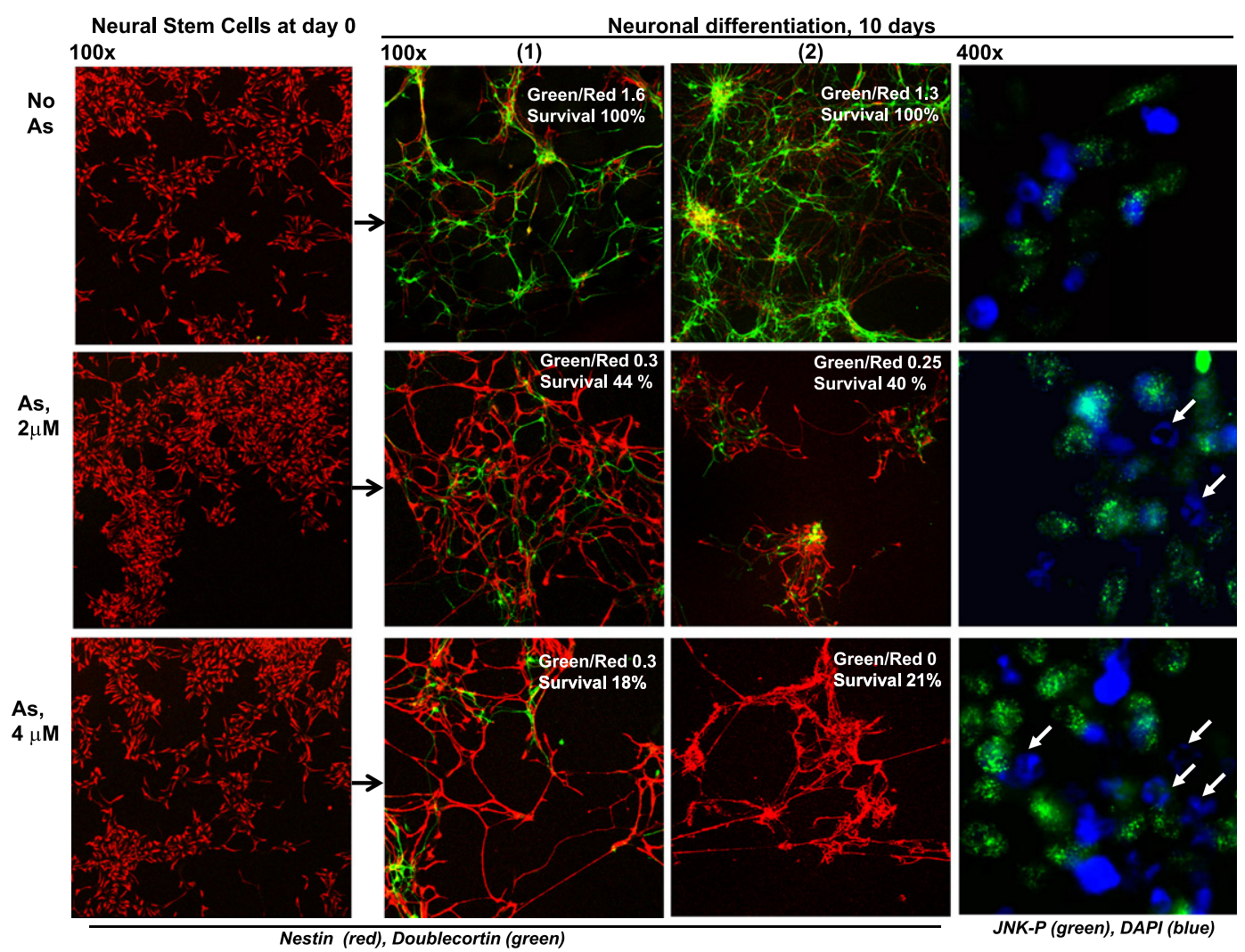

Fig. 6 - Neuronal differentiation of human NSC. Neuronal differentiation was initiated in the absence or in the presence of 2-4 $\mu \mathrm{M}$ sodium arsenite. Confocal analysis of immunofluorescent image was performed using monoclonal antibody against an early neuroprogenitor marker, nestin (red), and neuronal marker, doublecortin (green). The NSC before initiation of differentiation at day 0 and two representative images, (1) and (2), of each variant after 10 days of differentiation are shown. $A$ ratio of the number of green cells to the number of red cells and a relative cell survival ( 10 days after initiation of differentiation) is indicated. The right column demonstrates arsenite-induced JNK activation determined with anti-JNK-P Ab and DAPI staining of the nuclei. The white arrows indicate apoptotic nuclei.

effects of arsenite on cell survival during differentiation were less pronounced in the confluent culture (Supplementary Fig. 1B), probably due to increased endogenous production of surviving factors.

Inhibition of PI3K-AKT activation by small molecule inhibitors during neuronal differentiation is similar with negative effects of arsenite, which also suppresses AKT activity and substantially down-regulates neuronal differentiation. A combination of LY294002 and arsenite strongly decreased both relative cell survival and levels of the neuronal differentiation (Fig. 7). On the other hand, increased expression of phospho-ERK (Supplementary Fig. 2) and phospho-JNK (Fig. 6) were observed among differentiating cells following arsenite exposure. The question arose regarding the downstream effects of sodium arsenite-induced upregulation of ERK1/2 and JNK1 activities on regulation of neuronal differentiation.

Suppression of basal ERK1/2 or JNK activity with U0126 $(10 \mu \mathrm{M})$ and SP600125 $(20 \mu \mathrm{M})$, respectively, modestly retarded neuronal differentiation of NSC in the differentiation media (Fig. 8A and B). On the other hand, while inhibition of arsenite-induced ERK activity with U0126 modestly recovered differentiation of NSC, inhibition of arsenite-induced JNK activity with SP600125 resulted in massive cell killing with a substantially decreased yield of differentiating neurons (Fig. 8B). Interestingly, such a positive summary role of arsenite-induced JNK activation during neuronal differentiation was opposite to its proapoptotic role during arsenite treatment of human NSC (Fig. 5B). Hence, optimal levels of ERK activity were important for regulation of NSC proliferation, while overexpression of active ERK induced by sodium arsenite could partially suppress the normal pathway of neural differentiation. On the other hand, JNK activation was involved in numerous functions during neuronal differentiation [25,26] and inhibition of its activity either during normal differentiation or, especially, during arsenite exposure of neural progenitors resulted in upregulation of cell death and an additional suppression of neuronal differentiation (Fig. 8). Phosphorylated cJun, one of the main targets of JNK, could also be involved in transcriptional regulation of both apoptotic commitment and neuronal differentiation.

Taken together, results obtained demonstrated aggressive cytotoxic action of sodium arsenite (even at low doses such as $2-4 \mu \mathrm{M})$ that substantially disturbed normal neuronal differentiation of human NSC. 


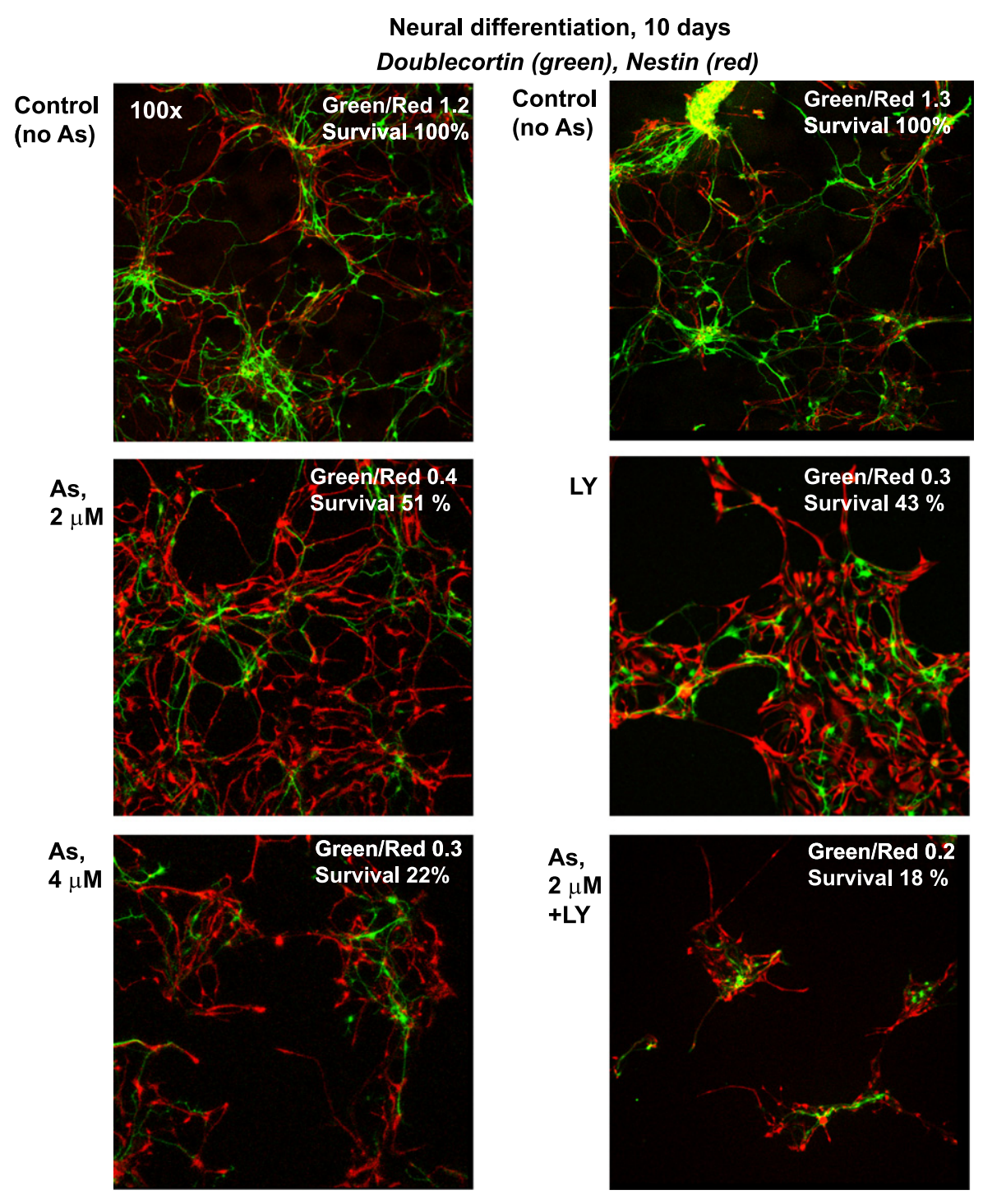

Fig. 7 - Effects of treatment with sodium arsenite alone or in combination with LY294002 $(40 \mu \mathrm{M})$ on neuronal differentiation of human NSC. Neuronal differentiation of NSC was performed in the differentiation medium in the absence or in the presence of 2-4 $\mu \mathrm{M}$ sodium arsenite, LY294002 or their combination. Confocal analysis was performed using Abs against nestin (red) and doublecortin (green). A ratio of the number of green (doublecortin-positive) cells to the number of red (nestin-positive) cells and a relative cell survival after $\mathbf{1 0}$ days are indicated.

\section{Discussion}

The results of the present study demonstrated that sodium arsenite treatment negatively regulated survival of human NSC by induction of the mitochondrial apoptotic pathway (Supplementary Fig. 3). Furthermore, the simultaneous suppression of the protective PI3K-AKT pathway further increased levels of cell death in NSC after sodium arsenite exposure. A pivotal role of PI3K-AKT in regulation of survival and self-renewal of pluripotent embryonic stem cells and multipotent neural stem cells has previously been reported [27-29]. AKT-dependent suppression of GSK3 $\beta$ activity that resulted in stabilization of protein levels of $\beta$-catenin was one of the essential events in regulation of proliferation and survival of human NSC [30]. Additionally, the PI3K-AKT pathway controls numerous cell functions, including activation of MTOR and general protein synthesis [31], and inactivation of proapoptotic activity of FOXO3A [23] that was also observed following sodium arsenite treatment of human NSC (see Fig. 3A and Supplementary Fig. 3).

We demonstrated in the present study that arsenite-induced mitochondrial damage accompanied by cytochrome-c release and caspase-9/caspase-3-dependent apoptosis substantially decreased a population of human multipotent NSC, even at low doses of sodium arsenite $(2-4 \mu \mathrm{M})$. Negative effects of arsenite exposure on some additional downstream targets of the PI3K-AKT pathway, including Nanog protein levels in NSC, were further determined in the present study (Fig. 4C; see also Supplementary Fig. 3). Paradoxically, there was a significant difference in regulation of protein expression levels of Sox2 in ESC versus NSC after arsenite treatment. We observed a strong dose-dependent down-regulation of Sox2 (in concert with Oct4 and Nanog) in mouse ESC (Ivanov and Hei, non-published data) 


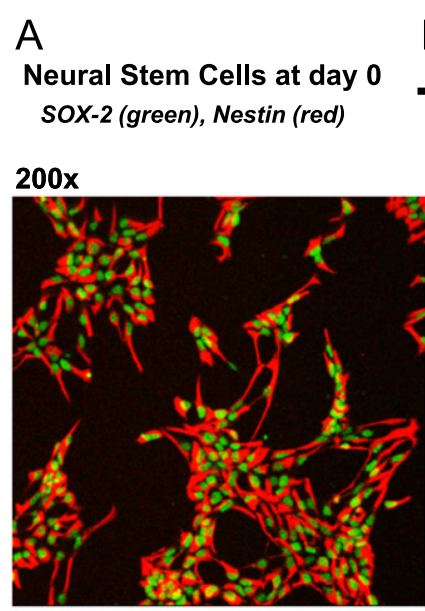

200x

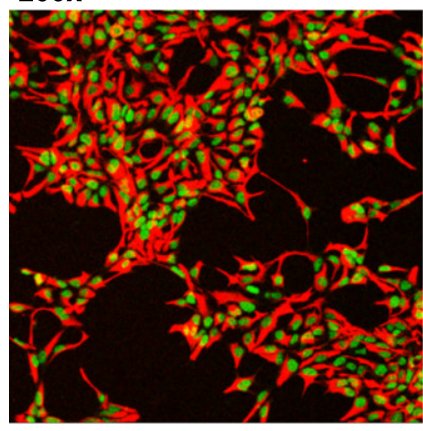

B

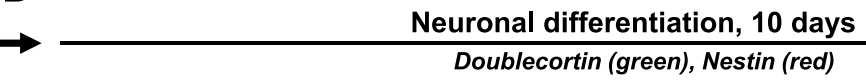

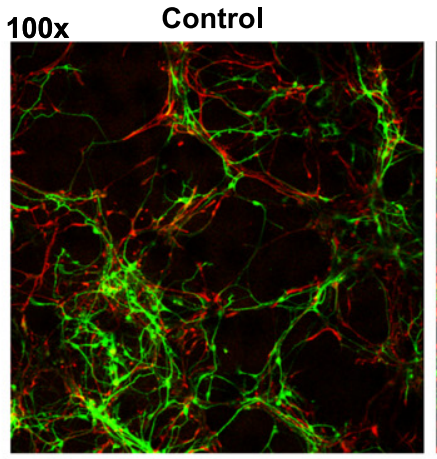

Green/Red 1.5 Survival $100 \%$

$100 x$

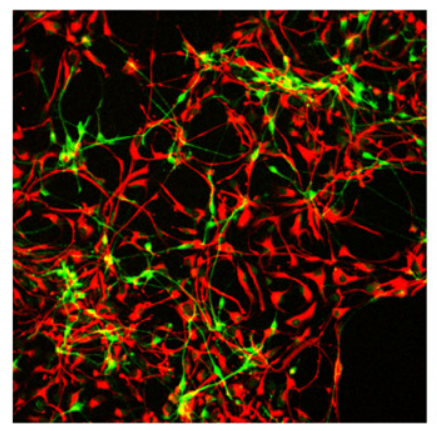

Green/Red $\mathbf{0 . 3}$ Survival $70 \%$

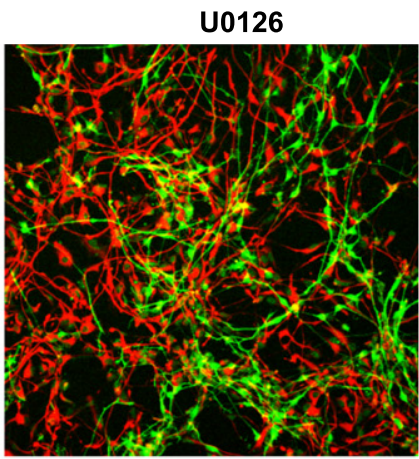

Green/Red 0.7 Survival $100 \%$

As + U0126

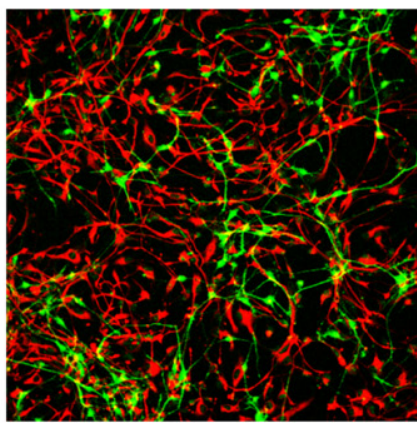

Green/Red 0.6 Survival $90 \%$

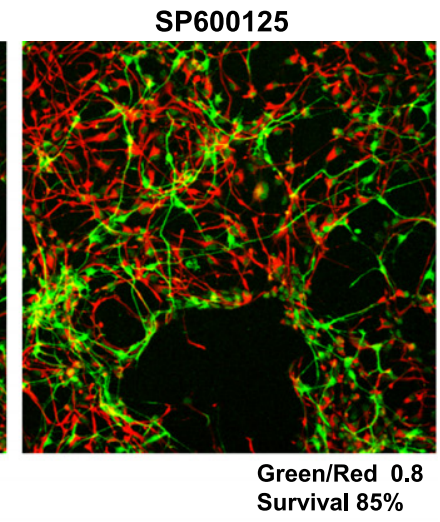

As + SP600125

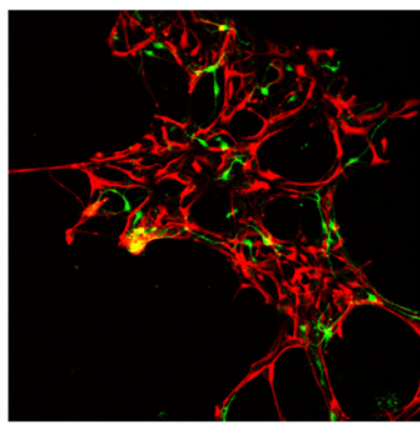

Green/Red 0.2

Survival $18 \%$

Fig. 8 - Effects of inhibition of sodium-arsenite-induced ERK and JNK1 activation on neuronal differentiation of human NSC. (A) NSC before induction of differentiation. (B) Neuronal differentiation of NSC was performed in the differentiation medium in the absence or in the presence $2 \mu \mathrm{M}$ sodium arsenite, U0126 $(10 \mu \mathrm{M})$, SP600125 $(20 \mu \mathrm{M})$ or their combinations. Cell markers determined by immunostaining are indicated. A ratio of the number of green (doublecortin-positive) cells to the number of red (nestin-positive) cells and a relative cell survival after $\mathbf{1 0}$ days are indicated.

and relatively stable Sox 2 protein levels, but strongly decreased Nanog levels in NSC 16-48 h after arsenite treatment (Figs. 3 and 4). Accordingly, immunostaining arsenite-treated NSC demonstrated that surviving cells exhibited pronounced protein expression of Sox2 (Fig. 1A and B). Interestingly, expression levels of Ars2, that was recently considered as a transcriptional regulator of Sox2 [15], were actually upregulated in the presence of arsenite (Fig. 3D). Our data indicated an AKT- and IKK/NF- $\kappa B-$ independent, but JNK/cJun-dependent manner of Sox2 expression in NSC. It could be a result of changes in transcription factor binding by the Sox 2 promoter, for example, from Oct4 in ESC to Oct1 in NSC [21,32] with the subsequent changes in regulation of the Sox 2 promoter activity by arsenite exposure.

Besides negative regulation of PI3K-AKT, down-regulation of IKK-NF- $\kappa B$ and JAK2-STAT3, activities by arsenite is a welldocumented phenomenon for many normal and cancer cells [33]. However, arsenite $(1-2 \mu \mathrm{M})$ treatment of NSC actually upregulated levels of active IKK-NF- $\mathrm{KB}$, probably, due to increased production of endogenous cytokines, such as TNF $\alpha$ [34] that is known as an inducer of NF-кB. The absence of arsenite-induced Stat3 downregulation in NSC could also be a result of its compensatory activation due to the endogenous cytokine production.
In summary, we demonstrated that arsenite exposure could dramatically change survival of NSC through induction of a massive apoptotic death. A question arose regarding quality and specificity of the neuronal differentiation of multipotent human NSC in the absence or in the presence of sodium arsenite. Our data revealed that neuronal differentiation of human NSC, which was initiated by FGF2 and EGF withdrawal, was strongly disturbed in the presence of $2-4 \mu \mathrm{M}$ arsenite, including pronounced morphological changes, a decrease in cell survival and a dramatic decrease in yield of differentiated cells (Fig. 6). These negative effects could be further enhanced by an additional inhibition of the PI3K-AKT pathway using LY294002 (Fig. 7). On the other hand, basal levels of JNK activity were linked with regulation of neural differentiation [25], and a suppression of basal and arsenite-induced JNK activation by specific inhibitor SP600125 resulted in suppression of differentiation and accelerated death of neural progenitor cells (Fig. 8). Arsenite-induced ERK activation during neuronal differentiation appeared to play the opposite role and actually increased proapoptotic commitment and suppressed differentiation. Consequently, its inhibition resulted in some protective effects during arsenic exposure of neural progenitor cells (Fig. 8). Interestingly, the recent study 
demonstrated that ERK inhibition by small molecule inhibitor of MEK-ERK rescued NF1-deficient neural progenitors (with strongly increased MEK-ERK activity leading to increased gliogenesis) from defects in fate specification and restored neurogenesis [35]. Beside JNK-cJun, the Notch pathway is critically involved in positive regulation of neural differentiation and suppression of proliferation in NSC [24]. Sodium arsenite was recently determined as an effective inhibitor of Notch signaling in normal human cells [36]. Inhibitory functions of sodium arsenite for the Notch signaling pathway need to be proved in NSC and neural progenitor cells.

We expect that investigation of signal-dependent regulation of gene expression driven by key transcription factors and modulating effects of sodium arsenite on gene expression in stem cells may open up new opportunities for understanding mechanisms of arsenic-mediated neurotoxicity.

\section{Acknowledgments}

We would like to thank Drs. Adayabalam Balajee, Mercy Davidson, Peter Grabham, Bo Zhang and Howard Lieberman for advice, critical reading of manuscript and discussion. This work was supported by NIH Grant P01 CA 049062 and Environmental Center Grant ES 009089. The authors declare that there are no conflicts of interest.

\section{Appendix A. Supporting information}

Supplementary data associated with this article can be found in the online version at http://dx.doi.org/10.1016/j.yexcr.2012.11.019.

\section{R E F E R E N C E S}

[1] M.P. Waalkes, J. Liu, B.A. Diwan, Transplacental arsenic carcinogenesis in mice, Toxicol. Appl. Pharmacol. 222 (2007) 271-280.

[2] A.H. Smith, G. Marshall, Y. Yuan, C. Ferreccio, J. Liaw, O. von Ehrenstein, C. Steinmaus, M.N. Bates, S. Selvin, Increased mortality from lung cancer and bronchiectasis in young adults after exposure to arsenic in utero and in early childhood, Environ. Health Perspect. 114 (2006) 1293-1296.

[3] A. Vahidnia, G.B. van der Voet, F.A. de Wolff, Arsenic neurotoxicity-a review, Hum. Exp. Toxicol. 26 (2007) 823-832.

[4] C.J. Chen, C.W. Chen, M.M. Wu, T.L. Kuo, Cancer potential in liver, lung, bladder and kidney due to ingested inorganic arsenic in drinking water, Br. J. Cancer 66 (1992) 888-892.

[5] A. Lindgren, B.R. Danielsson, L. Dencker, M. Vahter, Embryotoxicity of arsenite and arsenate: distribution in pregnant mice and monkeys and effects on embryonic cells in vitro, Acta Pharmacol. Toxicol. (Copenhagen) 54 (1984) 311-320.

[6] S.Y. Tsai, H.Y. Chou, H.W. The, C.M. Chen, C.J. Chen, The effects of chronic arsenic exposure from drinking water on the neurobehavioral development in adolescence, Neurotoxicology 24 (2003) 747-753.

[7] A. Mukherjee, M.K. Sengupta, M.A. Hossain, S. Ahamed, B. Das, B. Nayak, D. Lodh, M.M. Rahman, D. Chakraborti, Arsenic contamination in groundwater: a global perspective with emphasis on the Asian scenario, J. Health Popul. Nutr. 24 (2006) 142-163.
[8] E.T. Snow, Metal carcinogenesis: mechanistic implications, Pharmacol. Ther. 53 (1992) 31-65.

[9] M.D. Pulido, A.R. Parrish, Metal-induced apoptosis: mechanisms, Mutat. Res. 533 (2003) 227-241.

[10] T.K. Hei, S.X. Liu, C. Waldren, Mutagenicity of arsenic in mammalian cells: role of reactive oxygen species, Proc. Natl. Acad. Sci. U.S.A. 95 (1998) 8103-8107.

[11] S.X. Liu, M. Athar, I. Lippai, C. Waldren, T.K. Hei, Induction of oxyradicals by arsenic: implication for mechanism of genotoxicity, Proc. Natl. Acad. Sci. U.S.A. 98 (2001) 1643-1648.

[12] T. Graf, Historical origins of transdifferentiation and reprogramming, Cell Stem Cell 9 (2011) 504-516.

[13] J.H. Hanna, K. Saha, R. Jaenisch, Pluripotency and cellular reprogramming: facts, hypotheses, unresolved issues, Cell 143 (2010) 508-525.

[14] C. Zhao, W. Deng, F.H. Gage, Mechanisms and functional implications of adult neurogenesis, Cell 132 (2008) 645-660.

[15] C. Andreu-Agullo, T. Maurin, C.B. Thompson, E.C. Lai, Ars2 maintains neural stem-cell identity through direct transcriptional activation of Sox2, Nature 481 (2012) 195-198.

[16] B.A. Reynolds, S. Weiss, Generation of neurons and astrocytes from isolated cells of the adult mammalian central nervous system, Science 255 (1992) 1707-1710.

[17] I.W.G.o.t.E.o.C.R.t. Humans, Some drinking-water disinfectants and contaminants, including arsenic, IARC monographs on the evaluation of carcinogenic risks to humans/World Health Organization, International Agency for Research on Cancer 84 (2004) 1-477.

[18] P.M. Rodier, Developing brain as a target of toxicity, Environ. Health Perspect. 103 (6) (1995) 73-76.

[19] V.M. Rodriguez, M.E. Jimenez-Capdeville, M. Giordano, The effects of arsenic exposure on the nervous system, Toxicol. Lett. 145 (2003) 1-18.

[20] G.A. Wasserman, X. Liu, F. Parvez, H. Ahsan, P. Factor-Litvak, J. Kline, A. van Geen, V. Slavkovich, N.J. Loiacono, D. Levy, Z. Cheng, J.H. Graziano, Water arsenic exposure and intellectual function in 6-year-old children in Araihazar, Bangladesh, Environ. Health Perspect. 115 (2007) 285-289.

[21] K.L. Ring, L.M. Tong, M.E. Balestra, R. Javier, Y. Andrews-Zwilling, G. Li, D. Walker, W.R. Zhang, A.C. Kreitzer, Y. Huang, Direct reprogramming of mouse and human fibroblasts into multipotent neural stem cells with a single factor, Cell Stem Cell 11 (2012) 100-109.

[22] P. Koch, T. Opitz, J.A. Steinbeck, J. Ladewig, O. Brustle, A rosettetype, self-renewing human ES cell-derived neural stem cell with potential for in vitro instruction and synaptic integration, Proc. Natl. Acad. Sci. U.S.A. 106 (2009) 3225-3230.

[23] M.E. Carter, A. Brunet, FOXO transcription factors, Curr. Biol. 17 (2007) R113-R114.

[24] J.D. Hoeck, A. Jandke, S.M. Blake, E. Nye, B. Spencer-Dene, S. Brandner, A. Behrens, Fbw7 controls neural stem cell differentiation and progenitor apoptosis via Notch and c-Jun, Nat. Neurosci. 13 (2010) 1365-1372.

[25] P. Xu, M. Das, J. Reilly, R.J. Davis, JNK regulates FoxO-dependent autophagy in neurons, Genes Dev. 25 (2011) 310-322.

[26] S.J. Kim, T.G. Son, K. Kim, H.R. Park, M.P. Mattson, J. Lee, Interferongamma promotes differentiation of neural progenitor cells via the JNK pathway, Neurochem. Res. 32 (2007) 1399-1406.

[27] N.R. Paling, H. Wheadon, H.K. Bone, M.J. Welham, Regulation of embryonic stem cell self-renewal by phosphoinositide 3-kinasedependent signaling, J. Biol. Chem. 279 (2004) 48063-48070.

[28] S. Watanabe, H. Umehara, K. Murayama, M. Okabe, T. Kimura, T. Nakano, Activation of Akt signaling is sufficient to maintain pluripotency in mouse and primate embryonic stem cells, Oncogene 25 (2006) 2697-2707.

[29] M. Groszer, R. Erickson, D.D. Scripture-Adams, R. Lesche, A. Trumpp, J.A. Zack, H.I. Kornblum, X. Liu, H. Wu, Negative regulation of neural stem/progenitor cell proliferation by the Pten tumor suppressor gene in vivo, Science 294 (2001) 2186-2189. 
[30] J.E. Le Belle, N.M. Orozco, A.A. Paucar, J.P. Saxe, J. Mottahedeh, A.D. Pyle, H. Wu, H.I. Kornblum, Proliferative neural stem cells have high endogenous ROS levels that regulate self-renewal and neurogenesis in a PI3K/Akt-dependant manner, Cell Stem Cell 8 (2011) 59-71.

[31] I. Vivanco, C.L. Sawyers, The phosphatidylinositol 3-Kinase AKT pathway in human cancer, Nat. Rev. Cancer 2 (2002) 489-501.

[32] R. Catena, C. Tiveron, A. Ronchi, S. Porta, A. Ferri, L. Tatangelo, M. Cavallaro, R. Favaro, S. Ottolenghi, R. Reinbold, H. Scholer, S.K. Nicolis, Conserved POU binding DNA sites in the Sox2 upstream enhancer regulate gene expression in embryonic and neural stem cells, J. Biol. Chem. 279 (2004) 41846-41857.

[33] A.M. Bode, Z. Dong, The paradox of arsenic: molecular mechanisms of cell transformation and chemotherapeutic effects, Crit. Rev. Oncol. Hematol. 42 (2002) 5-24.
[34] R. Covacu, L. Arvidsson, A. Andersson, M. Khademi, H. Erlandsson-Harris, R.A. Harris, M.A. Svensson, T. Olsson, L. Brundin, TLR activation induces TNF-alpha production from adult neural stem/progenitor cells, J. Immunol. 182 (2009) 6889-6895.

[35] Y. Wang, E. Kim, X. Wang, B.G. Novitch, K. Yoshikawa, L.S. Chang, Y. Zhu, ERK inhibition rescues defects in fate specification of Nf1-deficient neural progenitors and brain abnormalities, Cell 150 (2012) 816-830.

[36] T.V. Reznikova, M.A. Phillips, R.H. Rice, Arsenite suppresses Notch1 signaling in human keratinocytes, J. Invest. Dermatol. 129 (2009) 155-161. 